\title{
Unusual cause of breast lump: a CSF pseudocyst
}

\author{
Sandeep Gopal Jakhere, MD, DNB \\ Raju Kumbhar, MD \\ Harshal Dhongade, MD
}

Department of Radiology, B Y L Nair Charitable Hospital and Topiwala National Medical College, Mumbai, Maharashtra, India

Corresponding author: S Jakhere (drsandeepjakhere@gmail.com)

\begin{abstract}
A ventriculoperitoneal (VP) shunt is a fairly common and useful procedure to reduce intracranial pressure in patients with hydrocephalus. Complications associated with VP shunts are usually related to either shunt obstruction or infection. A pseudocyst formation owing to leakage of CSF into the breast tissue as a complication of VP shunting is a rare entity, with few cases in the literature. Nonetheless, it is an important cause of cystic breast lump and should be kept in mind in a patient with an indwelling VP shunt. We describe the case of a 16-year-old girl patient with an indwelling VP shunt who presented with a gradually increasing breast lump, and was diagnosed to have a CSF pseudocyst based on characteristic imaging findings.
\end{abstract}

S Afr J Rad 2012;16(2):69-71.

A breast lump is an uncommon occurrence in the paediatric and adolescent patient; ${ }^{1}$ a majority of cases are either related to endocrine function or benign masses. ${ }^{2}$ The common benign causes are gynaecomastia, simple cyst, fibroadenoma, lymphnode, galactocoele, duct ectasia and infection. ${ }^{1}$ Malignant lesions are extremely rare in the paediatric and adolescent population, with an age-specific incidence of less than 25 cases per 100000 per year among patients younger than 19 years. $^{3}$ Cystic lesions account for approximately 7.2\% of breast lesions on ultrasound; an overwhelming majority are of benign aetiology (approximately 88\%). ${ }^{4}$ The common causes of cystic breast lesion include simple cyst, abscess, galactocoele and papilloma. A CSF pseudocyst of the breast has rarely been described in the literature, with only a few cases to date. ${ }^{5-11}$

\section{Case report}

A 16-year-old girl presented with pain in the right breast and a gradually increasing breast lump over the last 15 days. There was no history of fever. She was mentally retarded and had a history of tuberculous meningitis with multiple intraparenchymal tuberculomas at the age of 6 months. She had developed moderate hydrocephalus with thinning of the neuroparenchyma at that time, which was treated with a ventriculoperitoneal (VP) shunt.

She was referred for ultrasound study of the breast which showed a well-defined, thin-walled cystic lesion in the right breast. Moving internal echoes were seen within it. The VP shunt was seen passing through the cystic lesion. Since the cystic lesion was seen surrounding the VP shunt, a possibility of CSF leakage with resultant cyst formation was considered, and the patient was referred for CT scan of the brain, chest and abdomen to look for any other sites of CSF leakage. The brain CT revealed moderate hydrocephalus with several areas of encephalomalacia. The VP shunt was seen traversing the frontal horn of the right lateral ventricle, with its tip in the region of the suprasellar cistern. The chest CT showed a well-defined fluid collection in the right breast, measuring approximately $4.9 \times 2.9 \mathrm{~cm}$ with the VP shunt passing through it. Similar collections were also seen along the tract of the VP shunt in the right supraclavicular region and the lower anterior chest wall.

The abdominal CT showed an intraperitoneal fluid collection adjacent to the tip of the VP shunt measuring $7.9 \times 3.9 \mathrm{~cm}$. The collection appeared thin-walled and localised and displaced the adjacent bowel loops. In view of several fluid collections along the tract of the VP shunt, intraperitoneal collection adjacent to the tip of VP shunt and moderate hydrocephalus, a diagnosis of a CSF pseudocyst of the breast was made.

\section{Discussion}

Shunting of CSF into the peritoneal cavity in patients with hydrocephalus was advocated as far back as 1898 by Ferguson et al. ${ }^{12}$ However, it was only in 1905 that the first VP shunt was placed for CSF diversion. ${ }^{13}$ Although VP shunting has significantly improved outcomes in patients with hydrocephalus, it has been estimated that $40-50 \%$ of children and $29 \%$ of adults will suffer a shunt failure within the first year of placement. ${ }^{14}$ Complications associated with VP shunts are usually related to either shunt infection or obstruction. Obstruction of a VP shunt usually occurs at the proximal end, maybe caused by plugging of the catheter by brain parenchyma, the choroid plexus or tumour cells. Patients usually complain of headache, nausea, vomiting, lethargy, irritability and sometimes increasing head size with bulging fontanelles. Distal obstruction is usually caused by adhesions in the peritoneal cavity or apposition of solid abdominal organs against the shunt tip, which may lead to formation of abdominal pseudocysts that may present with increasing abdominal size and pain. Migration of a VP shunt may occur along the tract of its placement, and subsequent CSF drainage into the soft tissues occurs, leading to formation of CSF collections. The distal end of a VP shunt may migrate to unusual sites including the anus, umbilicus, vagina, scrotum, pulmonary artery or even the oral cavity. ${ }^{15}$

Thoracic complications associated with VP shunt placement are not very common, although they can sometimes be life-threatening. They are classified into 3 broad groups: ${ }^{15}$

1. complications occurring during shunt placement

2. complications related to catheter migration

3. pleural effusions.

Complications under the first group are infrequent, with only 3 cases reported up to 2007. A typical example is lung apex perforation while advancing the catheter during shunt placement, leading to pneumothorax. 


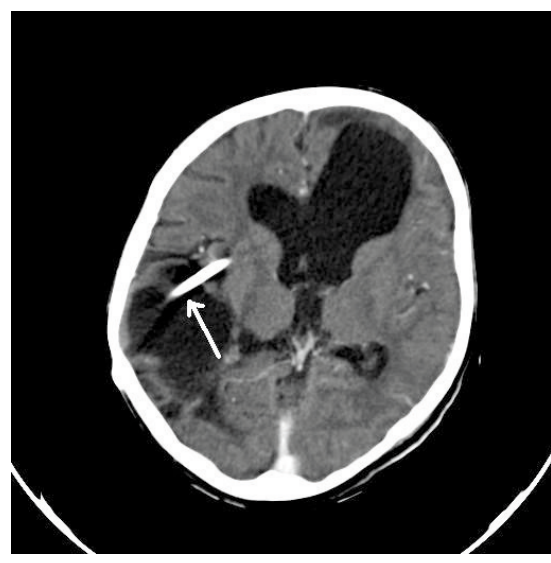

Fig. 1. Axial CT scan image of brain showing encephalomalacic changes in the right temporal lobe. Ex vacuo dilatation of the left frontal horn is seen. The VP shunt traverses the temporal lobe neuroparenchyma.

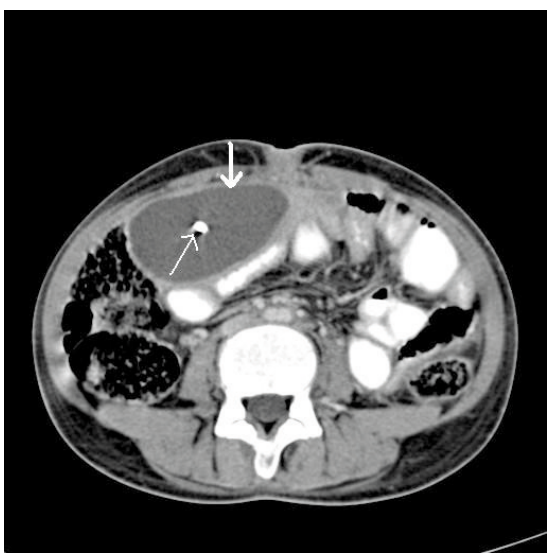

Fig. 4. Axial contrast-enhanced CT scan of the abdomen shows a well-defined thick-walled intra-peritoneal fluid collection (thick arrow) with the VP shunt (thin arrow) traversing it.

Thoracic migration of a VP shunt is also rather uncommon, with 12 cases reported. The distal tip of the VP shunt may migrate proximally along the chest wall, and may end up either in the pleural cavity or the lung parenchyma, with a few cases of bronchial perforation also being reported.

Pleural effusions are produced either due to supra diaphragmatic or transdiaphragmatic migration of the VP shunt; the treatment of choice is thoracocentesis.

Breast-related complications of a VP shunt include formation of pseudocysts and CSF galactorhea. CSF pseudocysts maybe formed in the breast either by migration of the catheter tip into the breast tissue or by fracture of the shunt followed by seepage of CSF and fluid accumulation. A few cases of a VP shunt wrapped around a breast prosthesis with subsequent CSF pseudocyst formation have also been reported..$^{16}$ Spector et al..$^{9}$ believed that migration of the VP shunt in their patient was related to lifting heavy weights, compounded by adhesions between the pectoralis major muscle and capsular tissues along the shunt tunnel, which caused significant traction force on the VP shunt. However, in our patient, there was no migration of the VP shunt tip, which remained in the abdominal cavity, and the CSF

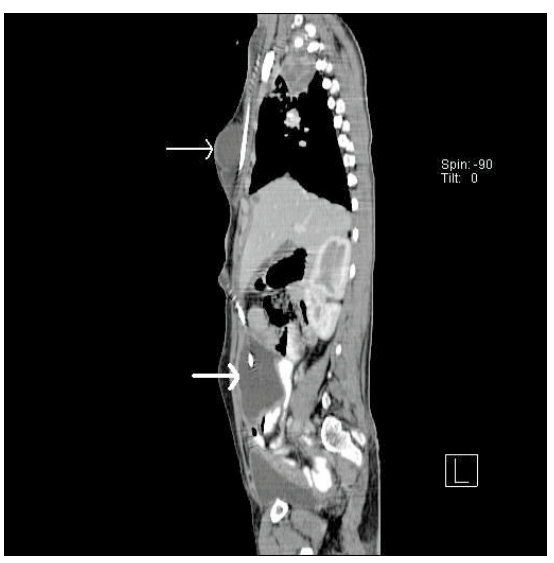

Fig. 5. Sagittal reformatted image showing the cystic lesion in the breast (thin arrow) and the intraperitoneal fluid collection (thick arrow).

pseudocyst formation was probably due to inadequate CSF drainage, as evidenced by abdominal pseudocysts and hydrocephalus, following a micro-fracture of the VP shunt in the region of the breast, and subsequent slow seepage of CSF.

In conclusion: CSF pseudocyst formation is a rare cause of a gradually enlarging breast lump, and should be borne in mind in patients with an indwelling VP shunt catheter. Ultrasound and CT evaluation would be diagnostic for this condition.

Acknowledgements. We thank Dr Bhakti Yeragi and Dr Vipul Chemburkar for evaluating the report for its content and accuracy.

1. Weinstein SP, Conant EF, Orel SG, Zuckerman JA, Bellah R. Spectrum of US findings in pediatric and adolescent patients with palpable breast masses. RadioGraphics 2000;20:1613-1621.

2. Amshell CE, Sibley E. Multiple unilateral fibroadenomas. Breast J 2001;7:189-191.

3. Ries LA, Eisner MP, Kosary CL, et al., eds. SEER Cancer Statistics Review, 1975-2002. Bethesda, MD: National Cancer Institute, 2005.

4. Berg WA, Campassi CI, Ioffe OB. Cystic lesions of the breast: sonographic-pathologic correlation. Radiology 2003;227:183-191.

5. Kalra N, Mani NB, Jain M, et al. Cerebrospinal fluid pseudocyst of the breast. Australas Radiol 2002;46:76-79.

6. Lazarus E, Nebres M, Spencer P, et al. Iatrogenic breast mass associated with a malfunctioning ventriculoperitoneal shunt in a patient with neurosarcoidosis. Am J Roentgenol 1998;171:529-530. 
7. Vimalachandran D, Martin L, Lafi M, et al. Cerebrospinal fluid pseudocyst of the breast. Breast 2003;12:215-216

8. Iyer HP, Jacob LP, Chaudhry NA. Breast cerebrospinal fluid pseudocyst. Plast Reconstr Surg 2006;118:87e-89e.

9. Spector JA, Culliford AT, Post NH, et al. An unusual case of cerebrospinal fluid pseudocyst in a previously augmented breast. Ann Plast Surg 2005;54:85-87.

10. Spector JA, Culliford IV AT, Levine JP. Breast cerebrospinal fluid pseudocyst. Plast Reconstr Surg 2007;120:357-358.

11. Torres AN, Barraquer EL, Salvador Sanz JF, et al. Late complication of a ventriculoperitoneal shunt in a patient with mammary prosthesis. J Plast Reconstr Aesthet Surg 2008;61:212-214.
12. Ferguson AH. Intraperitoneal diversion of the cerebrospinal fluid in cases of hydrocephalus. NY Med J 1898;67:902.

13. Harsh GR. Peritoneal shunt for hydrocephalus utilizing the fimbria of the fallopian tube for entrance to the peritoneal cavity. Neurosurgery 1954;11:284-294.

14. Kupeli E, Yilmaz C, Akcay S. Pleural effusion following ventriculo-pleural shunt: Case reports and review of the literature. Ann Thorac Med 2010;5:166-170.

15. Taub E, Lavyne MH. Thoracic complications of ventriculoperitoneal shunts: case report and review of the literature. Neurosurgery 1994;34:181-183.

16. Chu YT, Chuang HC, Lee HC, Cho DY. A ventriculoperitoneal shunt catheter wrapped around a right mammary prosthesis forming a pseudocyst. J Clin Neurosci 2010;17(6):801-803. 